\title{
Advanced Methods for Dispatching problems in Photolithography Area
}

\author{
Mohamad Pazlin bin Saion \\ Faculty of Manufacturing Technical University of Malaysia Malacca, \\ P051910004@student.utem.edu.my \\ https://orcid.org/ 0000-0001-8528-5057
}

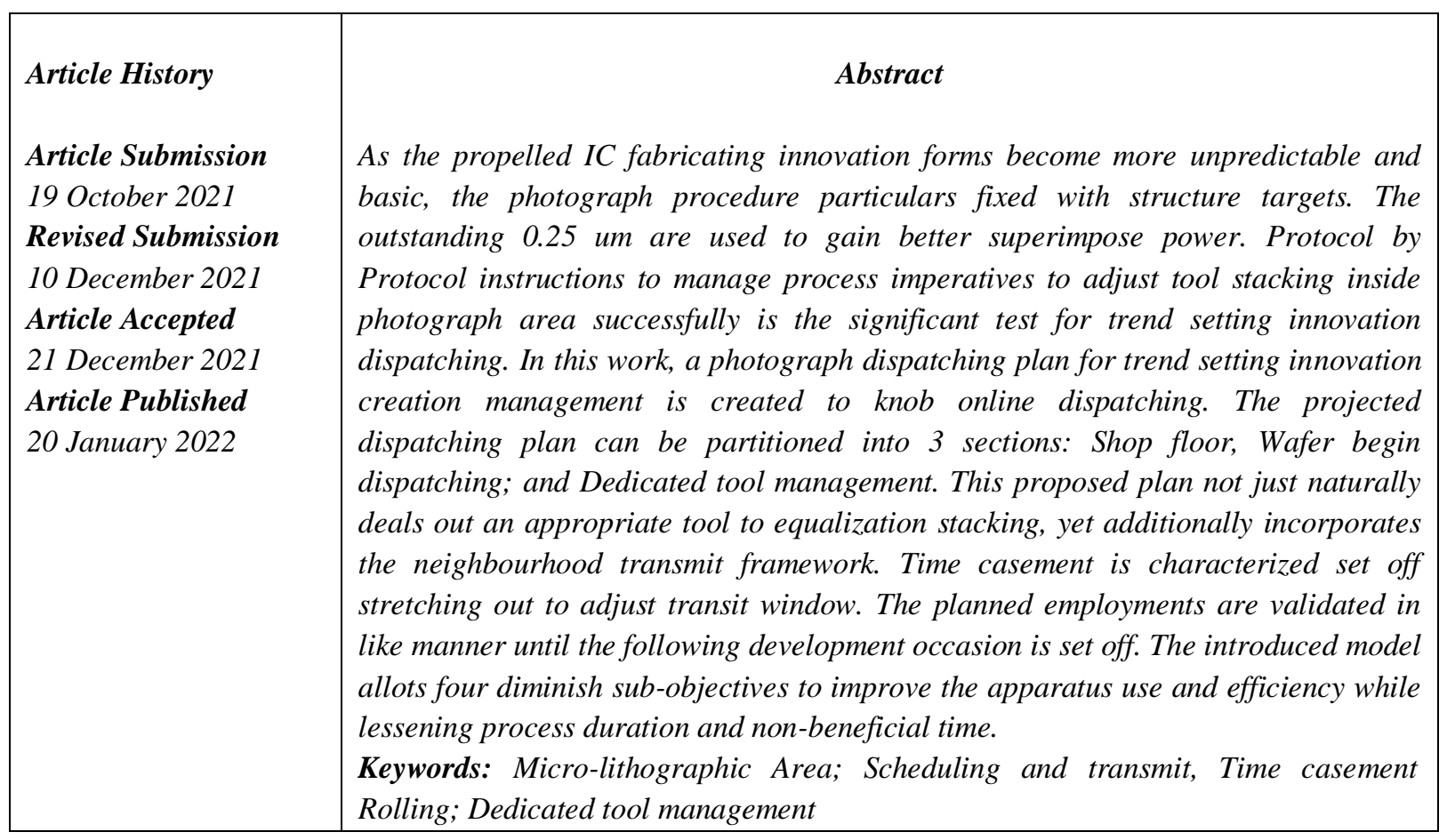

\section{Introduction}

The semiconductor producing process is profoundly mind boggling, costly, re-contestant and getting harder to adjust. In case of 0.30 um, the grouping of instrument used to uncover progressive layers has a modest effect. For forms underneath $0.25 \mathrm{um}$, notwithstanding, overlay turns into a basic piece of the general procedure spending plan, calling for more prominent overlay to meet more tight overlay prerequisites. The basic arrangement to devote overlay basic layers to instrument or instrument bunch for photograph forms. The significant assembling concern experienced are photograph cover distribution, tool ability limitations and same Protocol per requirements, and percentage between the stacking of basic and non-basic layers. The activities research writing contains countless papers on creation control. Notwithstanding, these investigations don't address the assembling issues with the photograph procedure limitations of trend setting innovation utilizing shop floor dispatching. A photograph dispatching plan is introduced here to manage the imperatives expressed above as calculation as referenced beneath.

Protocol 1: Figure the existing stacking of every contender tool.

Protocol 2: This activity bunches heaps of a similar item, with the goal that the calculation can dispatch them in succession to maintain a strategic distance from loads of a similar item being scattered. On the off chance that a couple of parcels are conveyed between numerous tools, specialists need to switch covers as often as possible and activity effectiveness will be diminished.

Protocol 3: Check parcel have been constrained to a solitary instrument in the first course. In the event that the parcel has been constrained to a solitary tool, at that point stop the estimations and go to stage 10; in any case, go to stage 4 . 
Protocol 4: Verify item, which the parcel has a place with, is recorded in the tool imperative table. In the event that indeed, at that point get the candidate tool list from the tool limitation table; in any case, get it from the tool bunch definition table.

Protocol 5: Twofold verify whether there is just a single candidate tool. In the event that truly, stop the computations and go to stage 10; in any case, go to stage 6.

Protocol 6: Verify if the item id of this parcel is equivalent to the past part. On the off chance that truly, go to stage 7; in any case, go to stage 9.

Protocol 7: Re-ascertain the stacking of the past chose instrument with including the parcel.

Protocol 8: Verify if the stacking of the past chose instrument after the part was alloted is inside the objective. The stacking objective is set as the normal stacking of different tools includes a consistent proportion that speaks to the stacking variety, for example, 5\%. On the off chance that the stacking of the preliminary computation is inside objective, at that point allot the parcel to the past chose tool and go to stage 10; in any case, go to stage 9.

Protocol 9: Dole out the part to the instrument with the lightest stacking.

Protocol 10: Feature the chose instrument on the MES PC.

Protocol 11: Re-figure the present stacking of the chose tool.

Protocol 12: In the event that all parts are allocated, the count closes; if not, return to stage 3.

Each mechanism in the micro-lithograph area has individual alignment attributes, which implies the circuit designs with wafer. So as to keep up steady track designs on basic layers. In this manner, when an apparatus is chosen to progression the main basic sheet for a wafer, the progressive basic sheet will be prepared in photolithography locale. These appliance devotion limitations muddle the development and transmit errands in the photograph area. At present, wafer packages are normally physically transmitted by who controls machine activities. Some of them are supported with data frameworks or basic choice standards to pull wafer parcels for machine handling. The general framework efficiency in this manner relies upon the dispatching encounters of the administrators on location. This work proposes a unique scheduling technique for the employments in the photograph area dependent on the need, as appeared in Fig 1, that considers arrangement time decreasing, load adjusting, day by day creation objective coordinating, throughput upgrading, and process duration diminishing as appeared in Table 1.

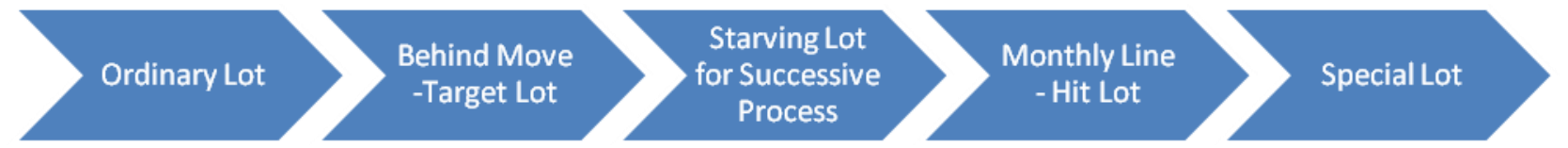

Low Priority

High Priority

Figure 1. Five Priorities Release for Distributing Scheme

Table 1: The Averaged Operational Indices from Different Time Window Sizes

\begin{tabular}{|c|c|c|c|c|}
\hline Time Window & $\begin{array}{c}\text { Average } \\
\text { Utilization }\end{array}$ & Throughput & $\begin{array}{c}\text { Average Cycle } \\
\text { Time }\end{array}$ & Extra Time \\
\hline 0 & 0.915 & 2348.52 & 3.84 & 196.32 \\
\hline 30 & 0.918 & 2362.76 & 4.76 & 195.78 \\
\hline 60 & 0.914 & 2375.38 & 3.98 & 196.98 \\
\hline 90 & 0.919 & 2344.98 & 5.23 & 191.23 \\
\hline 120 & 0.893 & 2332.69 & 7.98 & 188.56 \\
\hline 150 & 0.832 & 2321.72 & 9.42 & 189.17 \\
\hline
\end{tabular}




\section{References}

[1] Shr, A. Liu, et al., "A heuristic scheduling approach to the dedicated machine constraint.," International Journal on Artificial Intelligence Tools 17 (2), 2008, pp. 339-353.

[2] W. L. Pearn, S. H. Chung, et al., "Solution strategies for multi-stage wafer probing scheduling problem with reentry," Journal of the Operational Research Society 59 (5), 2008, pp. 637-651.

[3] Z. Wang, Q. Wu, et al., "A lot dispatching strategy integrating WIP management and wafer start control," Automation Science and Engineering, IEEE Transactions on [see also Robotics and Automation, IEEE Transactions on] 4 (4), 2007, pp.579-583. 